\title{
Expression of matrix metalloproteinases and tissue inhibitor of matrix metalloproteinases in the hair cycle
}

\author{
CHUN HOU, YONG MIAO, XUE WANG, CHAOYUE CHEN, BOJIE LIN and ZHIQI HU \\ Department of Plastic and Cosmetic Surgery, Nanfang Hospital, Southern Medical University, \\ Guangzhou, Guangdong 510515, P.R. China
}

Received February 6, 2015; Accepted March 15, 2016

DOI: 10.3892/etm.2016.3319

\begin{abstract}
According to the growth state of hair follicles, the hair cycle is divided into the anagen, catagen and telogen phases. A number of biological factors have been shown to synchronize with the hair cycle. As an important component of the hair follicle, the extracellular matrix is regulated by matrix metalloproteinases (MMPs) and their inhibitors (tissue inhibitor of matrix metalloproteinases; TIMPs). It has been reported that MMP-2, MMP-9 and TIMP-1 are associated with the hair cycle; however, their expression levels during the hair cycle have not been fully elucidated. Reverse transcription-polymerase chain reaction and ELISA analysis in the present study demonstrated that, during the hair cycle in mice, mRNA and protein expression levels of MMP-2 and MMP-9 were elevated in the anagen phase, and decreased during the catagen and telogen phases. Furthermore, SDS-PAGE gelatin zymography demonstrated that their activities fluctuated in the hair cycle. Additionally, it was observed that the mRNA and protein expression levels of TIMP-1 and TIMP-2 were negatively correlated with MMP-9 and MMP-2, respectively. Immunohistochemical examination demonstrated that MMP-2 and TIMP-2 were present in all structures of the hair follicle. However, MMP-9 and TIMP-1 were locally expressed in certain areas of the hair follicle, such as in the sebaceous gland at the anagen, catagen and telogen phases, and in the inner root sheath at the catagen phase. These results suggested that MMP-2 and MMP-9 may serve an important role in the hair growth cycle.
\end{abstract}

Correspondence to: Dr Zhiqi Hu, Department of Plastic and Cosmetic Surgery, Nanfang Hospital, Southern Medical University, 1838 Guangzhou Avenue North, Guangzhou, Guangdong 510515, P.R. China

E-mail: doctorhzq@hotmail.com

Key words: matrix metalloproteinases, MMP-2, MMP-9, tissue inhibitor of matrix metalloproteinases, TIMP-2, hair cycle

\section{Introduction}

The hair cycle is an intrinsic and cyclic system of regenerating tissue (1), which is composed of the anagen (phases of rapid growth; 1-3 weeks), catagen (phases of apoptosis-driven regression; $\sim 2$ days) and telogen (phases of relative quiescence; $\sim 2$ weeks) phases (Fig. 1). The growth of hair is considered to be a result of the cyclic remodeling of the follicle (2). There are numerous biological factors that regulate or synchronize with the hair cycle (3), such as hormones, growth factors, enzymes and transcriptional factors. Enzymes include ornithine decarboxylase, aromatase and nexin 1 . The hair cycle is considered to be a process of tissue regeneration associated with extracellular matrix (ECM) degradation and remodeling (4).

Matrix metalloproteinases (MMPs) are a family of zinc-dependent endopeptidases that can be produced by a number of different types of cells in the skin, including fibroblasts, keratinocytes, macrophages, endothelial cells, mast cells and eosinophils (5). MMPs consist of at least 19 cloned membranes, including the type IV collagenases (such as MMP-2 and MMP-9), metalloelastase, interstitial collagenase, stromelysins, matrilysins and membrane-type MMPs. In addition, increasing evidence demonstrates that MMPs can affect the signaling pathways associated with various factors, such as insulin-like growth factor-binding protein-3, tumor necrosis factor- $\alpha$ (TNF- $\alpha$ ), fibroblast growth factor receptor 1 and angiogenic factors (6-10). MMP-2 and MMP-9 are important members of the MMP superfamily, since they can degrade gelatin, collagen IV, V, VII and X, fibronectin, and elastin (9-13).

The expression levels of MMP-2 and MMP-9 are reported to be regulated by numerous factors. For instance, MMP-2 is regulated by transforming growth factor (TGF)- $\beta$, interleukin (IL)- $1 \beta$ and interferon (IFN) in certain fibroblasts (14-17), and Wnt in T cells (18). Similarly, MMP-9 is induced by several regulators, including epidermal growth factor, TGF- $\alpha$, TGF- $\beta$, IL- $1 \beta$ and IFN- $\alpha(16,19-23)$. The activities of MMP-2 and MMP-9 are specifically inhibited by tissue inhibitor of matrix metalloproteinases (TIMP)-2 and TIMP-1, respectively (24), which may be vital in the regulation of connective tissue metabolism and remodeling in numerous different organ systems, including hair follicle.

There are a few studies investigating the relationship between MMP-2, MMP-9, TIMP-1 and the hair cycle (25). 


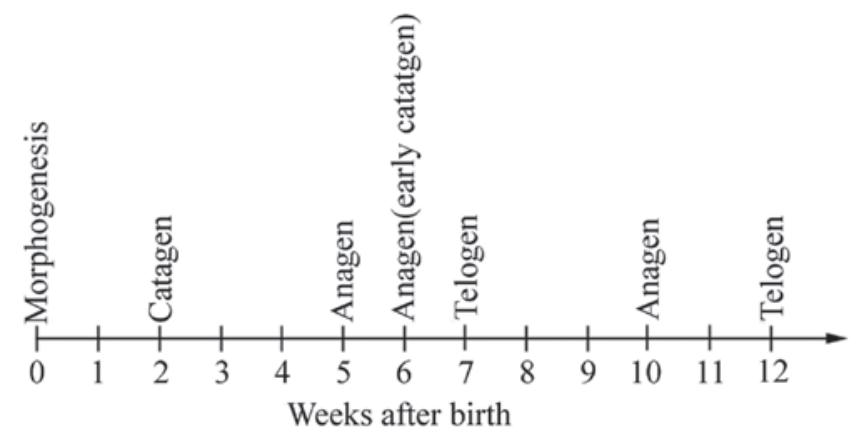

Figure 1. Time-scale of the hair cycle in female C57BL/6 mice during the first 12 weeks after birth.

MMP-2, MMP-9 and TIMP-1 have been suggested to be associated with the hair cycle in vitro and in vivo (26). In addition, the expression profiles of MMP-2, MMP-9, TIMP-1 and TIMP-2 in the hair cycle remain unclear. Therefore, the present study aimed to investigate the expression levels of MMP-2, MMP-9, TIMP-1 and TIMP-2 throughout the hair cycle in mice.

\section{Materials and methods}

Materials. Rabbit polyclonal antibodies against MMP-2 (cat. no. ab37150), MMP-9 (cat. no. ab38898), TIMP-1 (cat. no. ab61224) and TIMP-2 (cat. no. ab180630) were purchased from Abcam (Cambridge, MA, USA) and were all diluted to a concentration of 1:1,000. The ELISA kits were purchased from Thermo Fisher Scientific, Inc. (Waltham, MA, USA; cat. nos. KHC3081, KHC3061, KHC1491 and EHTIMP2).

Animals. Female C57BL/6 mice ( $\mathrm{n}=5$ at each week of age) aged between 3 and 12 weeks (weight range, 9-23 g) were purchased from the Laboratory Animal Center of Guangzhou University of Chinese Medicine (Guangzhou, China). All animal experiments were performed in strict accordance with the recommendations in the Guide for the Care and Use of Laboratory Animals (2014). The mice had access to food and water ad libitum, and were housed in a controlled environment (temperature, $23 \pm 2^{\circ} \mathrm{C}$; humidity, $55 \pm 10 \% ; 12 \mathrm{~h}$ light/dark cycle). To collect skin biopsies at each stage of the hair cycle, 6 mice at each week of age were used in this study. To ameliorate animal welfare, the animals were used at a minimum number during the study. As the mice reached their desired age, they were sacrificed by $\mathrm{CO}_{2}$ gas inhalation. To obtain specific hair cycle stage specimens, the dorsal skin of each mouse was excised from just below the line connecting the scapulas. Each skin specimen was separated from the subcutaneous tissue and was sampled by punch biopsy for the examinations. Ethical approval was obtained from the Ethics Committtee of Guangzhou University of Chinese Medicine (approval no. 20141406-63).

Enzyme activity measurement. MMP-2 and MMP-9 activities were measured by $10 \%$ SDS-PAGE gelatin zymography as previously described (24). Briefly, without boiling or reduction, the samples (12 $\mu \mathrm{l}$ sample, $4 \mu \mathrm{l}$ loading buffer) were fractionated in an SDS-polyacrylamide gel containing $0.1 \%$ gelatin by electrophoresis at $100 \mathrm{~V}$ for $90 \mathrm{~min}$ at $4^{\circ} \mathrm{C}$. Next, the gels were incubated in a digestion buffer (Shanghai Ann Inquiry Trading Co., Ltd., Shanghai, China) with bivalent metal ions to recover the activities of MMP-2 and MMP-9. Subsequent to rinsing in distilled water, the gels were stained with Coomassie brilliant blue (Beijing Seitz Biotechnology Co., Ltd., Beijing, China), and then destained. Gelatinolytic activity appeared as clear bands of digested gelatin against a dark blue background of stained gelatin. The intensity of the bands was measured using with Alpha Imager HP and AlphaView software (version 1.0; ProteinSimple, San Jose, CA, USA), and was proportional to the activities of MMP-2 and MMP-9.

Reverse transcription-polymerase chain reaction (RT-PCR). Total RNA in the skin samples was isolated with TRIzol reagent (Invitrogen; Thermo Fisher Scientific, Inc.). The RNA was quantified by measuring the absorption at $260 \mathrm{~nm}$ using NanoDrop 2000 (Thermo Fisher Scientific, Inc.), and the purity of the RNA was assayed by the ratio of absorbance at $260 \mathrm{~nm}$ and $280 \mathrm{~nm}$. A fraction was electrophoresed with $1 \%$ agarose to verify its integrity. The total RNA of each sample was then reverse transcribed into cDNA with SuperScript III Reverse Transcriptase (Thermo Fisher Scientific, Inc.). PCR was performed to measure the mRNA levels of MMP-2, MMP-9, TIMP-1 and TIMP-2, using the primers (synthesized by Invitrogen; Thermo Fisher Scientific, Inc.) presented in Table I. In a $15 \mu 1$ system containing $7.5 \mu 12 \mathrm{X}$ qPCR master

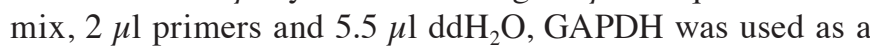
housekeeping gene and mRNA expression was analyzed using an RT-PCR system (AB17500; Applied Biosystems, Foster City, CA, USA) and the following thermal cycling conditions: 40 cycles at $50^{\circ} \mathrm{C}$ for $2 \mathrm{~min}, 95^{\circ} \mathrm{C}$ for $2 \mathrm{~min}, 95^{\circ} \mathrm{C}$ for $15 \mathrm{sec}$ and $60^{\circ} \mathrm{C}$ for $32 \mathrm{sec}$.

Enzyme-linked immunosorbent assay (ELISA). The expression levels of MMP-2, MMP-9, TIMP-1 and TIMP-2 in the skin were detected using ELISA kits, according to the manufacturer's instructions. Briefly, $100 \mu 1$ prepared standard or sample (1:40 dilution) was added to each well and incubated for $2 \mathrm{~h}$ at room temperature. The plates were then washed with buffer four times. Following washing, $100 \mu \mathrm{l}$ biotinylated labeled primary antibody was added to the wells, and the plates were incubated for $1 \mathrm{~h}$ at room temperature. After washing four times with buffer, the plates were incubated with peroxidase-conjugated secondary antibody for $45 \mathrm{~min}$. The plates were washed three times, and $100 \mu 1$ Streptavidin-HRP 
Table 1. Primer pair sequences used in reverse transcription-polymerase chain reaction.

\begin{tabular}{lcc}
\hline Gene & Forward primer & \multicolumn{1}{c}{ Reverse primer } \\
\hline GAPDH & 5'-GGCCTCCAAGGAGTAAGAAA-3' & 5'-GCCCCTCCTGTTATTATGG-3' \\
MMP-2 & 5'-ATCGCAGACTCCTGGAATG-3' & 5'-CCAGCCAGTCTGATTTGATG-3' \\
MMP-9 & 5'-TCCAGTACCAAGACAAAGC-3' & 5'-GAGCCCTAGTTCAAGGGCAC-3' \\
TIMP-1 & 5'-AGTCCCAGAACCGCAGTGAA-3' & 5'-AGAGTACGCCAGGGAACCAA-3' \\
TIMP-2 & 5'-GGTAGCCTGTGAATGTTCCT-3' & 5'-ACGAAAATGCCCTCAGAAG-3'
\end{tabular}

MMP, matrix metalloproteinase; TIMP, tissue inhibitor of matrix metalloproteinase.

Working Solution was added to each well (except the chromogen blanks) to induce the color reaction at room temperature for $30 \mathrm{~min}$. The assay was stopped at $20-25 \mathrm{~min}$. The optical density at $450 \mathrm{~nm}$ was determined using an automated microplate reader (ELx808) and Gen5 Data Analysis Software (version 2.0) (both purchased from BioTek, Shoreline, WA, USA).

Immunohistochemical analysis. The collected samples for immunohistochemical examination were promptly fixed in $10 \%$ formalin solution. Following dehydration and embedding in paraffin, skin sections of $\sim 3 \mu \mathrm{m}$ in size were prepared, deparaffinized and incubated with $3 \% \mathrm{H}_{2} \mathrm{O}_{2}$ at room temperature for 5-10 $\mathrm{min}$ in order to eliminate the endogenous peroxidase activity. For histopathological examination, the sections were stained with hematoxylin and eosin (Beijing Seitz Biotechnology Co., Ltd.). For immunohistochemical examination, the sections were processed with antigen repair and blocking, according to a previous study $(27,28)$. Briefly, slides in $0.01 \mathrm{M}$ sodium citrate buffer (Sigma-Aldrich, St. Louis, MO, USA), pH 6.0, were incubated at $99-100^{\circ} \mathrm{C}$ for $20 \mathrm{~min}$. Slides were then removed from heat and kept in cool buffer at room temperature for $20 \mathrm{~min}$ and rinsed in Tris-buffered saline with 0.1\% Tween-20 (Aviva Systems Biology Corporation, San Diego, CA, USA) at room temperature for $1 \mathrm{~min}$. Following incubation overnight at $4^{\circ} \mathrm{C}$ with primary antibodies against MMP-2, MMP-9, TIMP-1 and TIMP-2 separately, the samples were exposed to horseradish peroxidase-conjugated anti-rabbit IgG secondary antibody (1:5,000 dilution; cat. no. W4011; Promega Corporation, Madison, WI, USA). Subsequently, DAB (Cell Signaling Technology, Inc., Danvers, MA, USA) was used to visualize the expression of proteins stained with hematoxylin and eosin.

\section{Results}

Fluctuation of MMP-2 and MMP-9 activities throughout the hair cycle. To investigate the correlation between MMP-2, MMP-9 and the hair cycle, the activities of MMP-2 and MMP-9 were determined using samples of dorsal skin, including the hair follicle. As presented in Fig. 2A, the enzyme activities were present at each phase of the hair cycle. The activity of MMP-2 fluctuated in the hair cycle; the activity peaked at 6 and 10 weeks during the anagen phase, decreased during the catagen phase, and reached its lowest level of activity at 7 and 12 weeks during the telogen phase of the hair cycle (Fig. 2B).
Similarly, the activity of MMP-9 fluctuated, with a peak at 6 and 10 weeks (Fig. 2C). Typical histopathological images of each stage during the hair cycle are presented in Fig. 2D. Cells in the cytoplasm during the anagen phase were light or mild alkalophilic by eosin coloration, and were eosinophilic with aging or degeneration.

Fluctuation of MMP-2, MMP-9, TIMP-1 and TIMP-2 mRNA and protein expression levels throughout the hair cycle. To determine whether the expression of the enzymes of MMP-2 and MMP-9 fluctuated, RT-PCR and ELISA were performed in order to determine the mRNA and protein expression levels, respectively, of each protein. As shown in Figs. 3 and 4, the mRNA and protein expression levels of the enzymes were similar and detectable throughout the hair cycle. The expression of each protein fluctuated, with a peak at 5 and 10 weeks, and a decrease at 7 and 12 weeks, as is expected in the hair cycle (29).

In addition, the expression levels of TIMP-1 and TIMP-2 were determined for comparison against their targets, MMP-9 and MMP-2, respectively. Figs. 3 and 4 show the fluctuations in the mRNA and protein expression levels of the TIMPs. mRNA and protein expression levels were the lowest at 6 and 10 weeks, which corresponded to the anagen phase, and were then increased during the catagen phase, reaching peak levels at 7 and 12 weeks during the telogen phase. These results indicate that the expression levels of TIMP are negatively correlated with the MMP expression levels.

Localization of MMP-2, MMP-9, TIMP-1 and TIMP-2 throughout the hair cycle. To identify the expression sites of MMP-2, MMP-9, TIMP-1 and TIMP-2 at each stage of the hair cycle, immunohistochemical analysis was performed (Fig. 5). Positive staining for MMP-2 and TIMP-2 was almost observed throughout the entire hair follicle at each stage, although the expression was most intense during the anagen (early catagen) phase. Positive staining was observed for MMP-9 and TIMP-1 locally in the hair follicle, such as in the sebaceous gland during the anagen and catagen phases, and in the inner root sheath during the catagen phase.

\section{Discussion}

The mechanism underlying the hair cycle has been widely studied, whereas the factors involved have yet to be elucidated. MMPs and TIMPs are important regulators, participating 
A

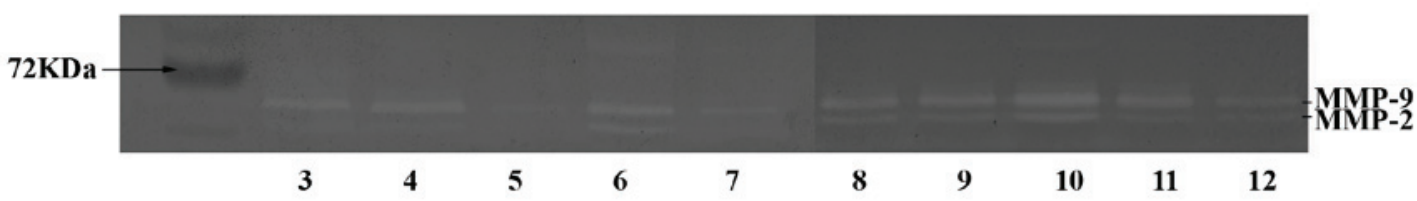

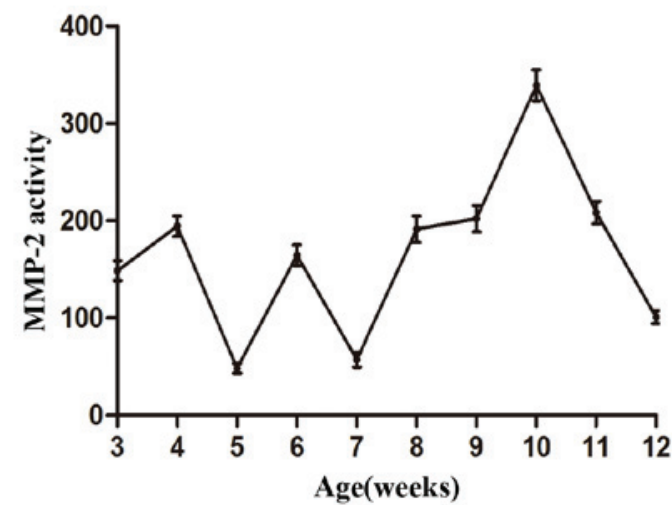

C

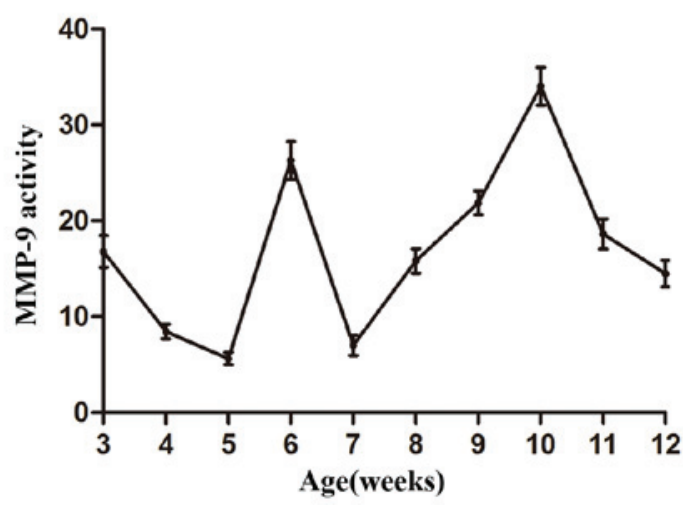

D

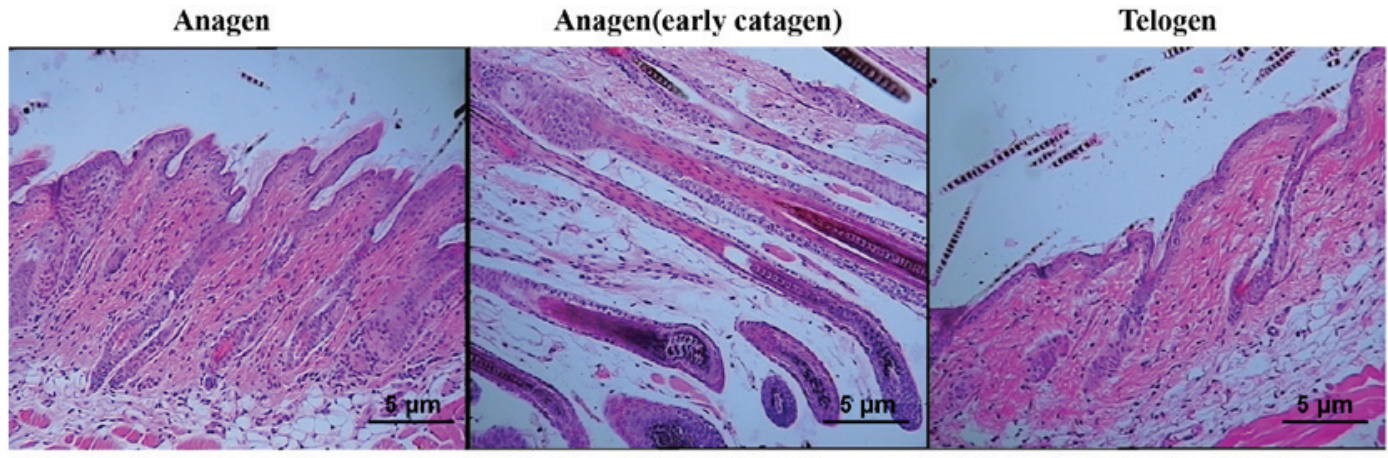

Figure 2. MMP-2 and MMP-9 activity at each stage of the mouse hair cycle. (A) Gelatin zymography of MMP-2 and MMP-9 activity; quantification of (B) MMP-2 and (C) MMP-9 activity; and (D) immunohistochemical analysis of skin samples at anagen (4 weeks), early catagen (6 weeks) and telogen (10 weeks) phases, stained with hematoxylin and eosin (scale bar, $0.1 \mathrm{~mm}$ ). MMP, matrix metalloproteinase.

A

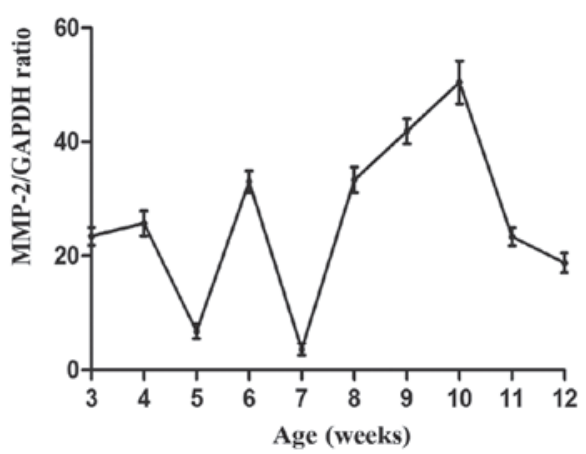

C

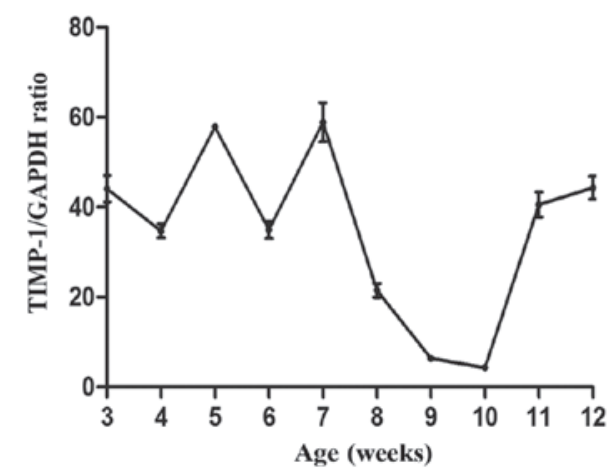

B

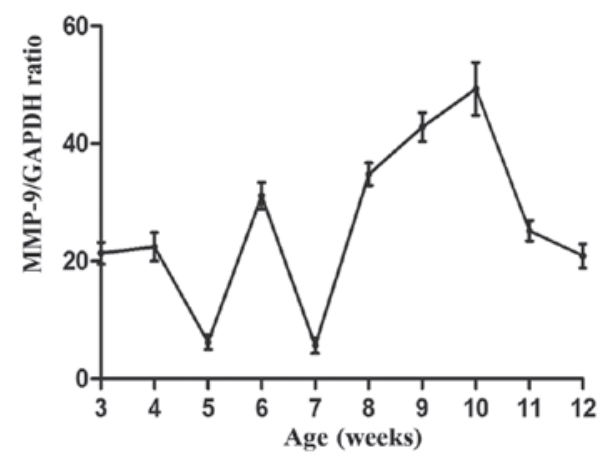

D

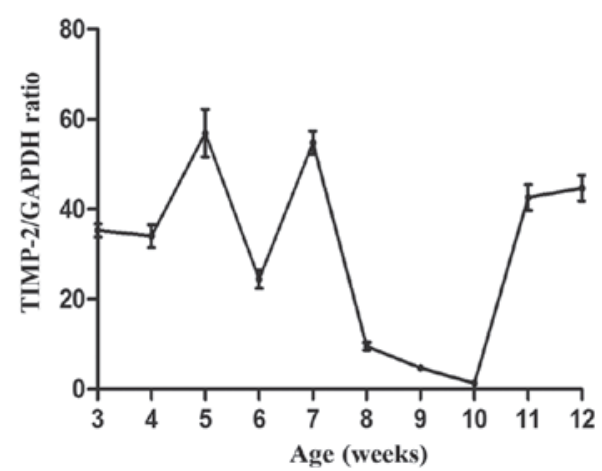

Figure 3. mRNA expression levels of (A) MMP-2, (B) MMP-9, (C) TIMP-1 and (D) TIMP-2, normalized to GAPDH. MMP, matrix metalloproteinase; TIMP, tissue inhibitor of matrix metalloproteinase. 

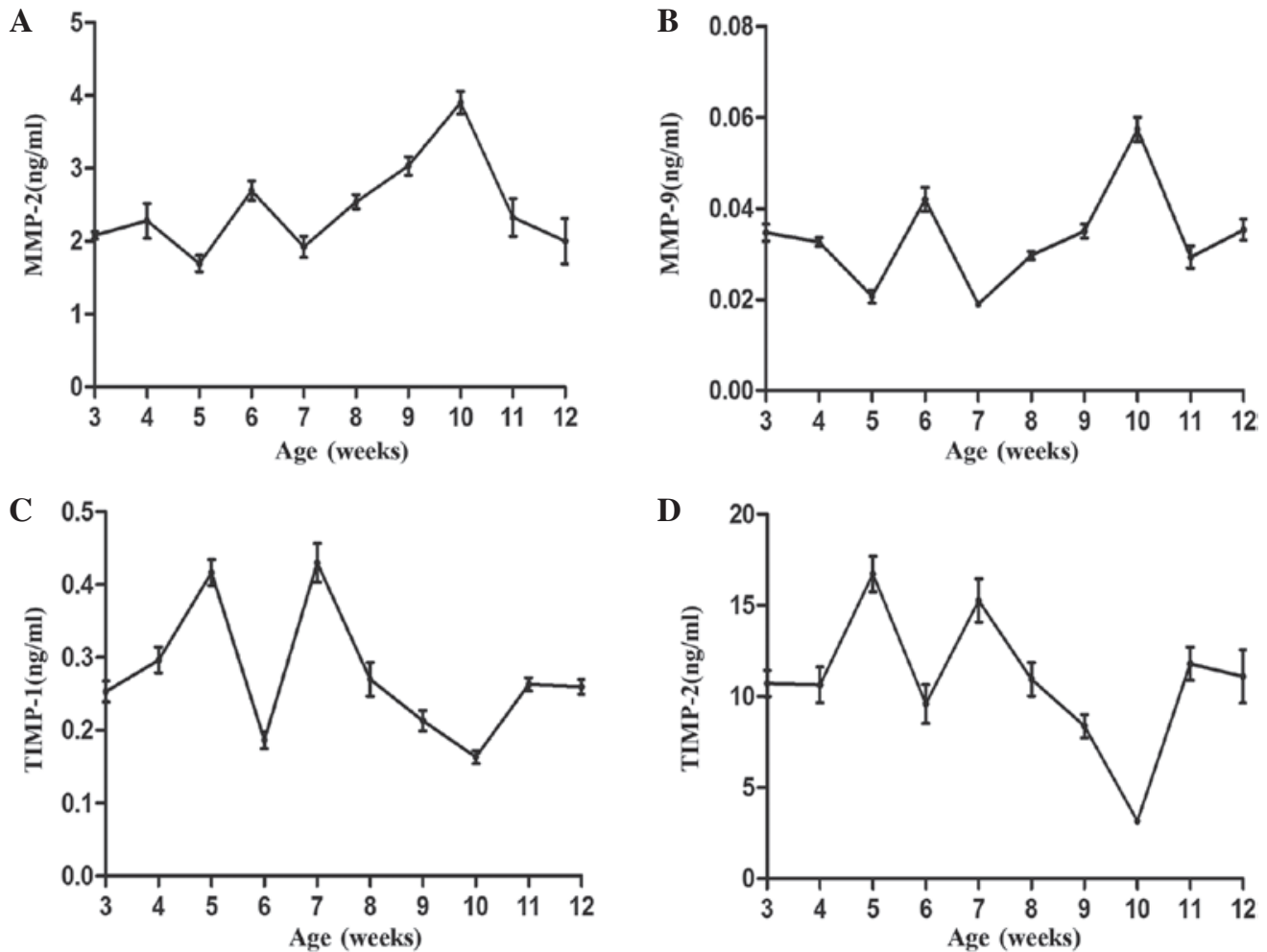

Figure 4. Protein expression levels of (A) MMP-2, (B) MMP-9, (C) TIMP-1 and (D) TIMP-2. MMP, matrix metalloproteinase; TIMP, tissue inhibitor of matrix metalloproteinase.

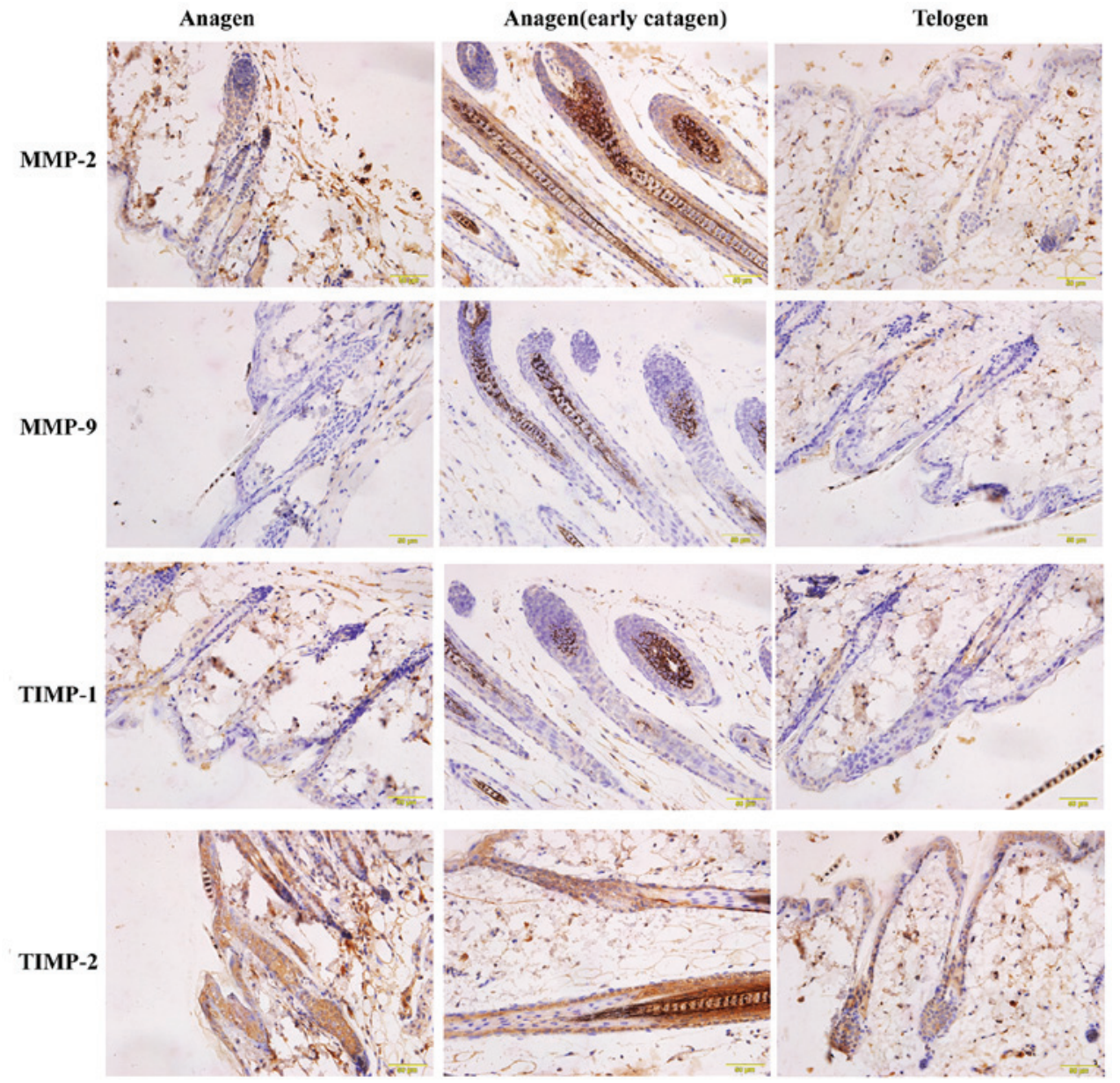

Figure 5. Localization of MMP-2, MMP-9, TIMP-1 and TIMP-2 at each stage of the hair cycle in mice. Brown staining identifies the proteins. MMP, matrix metalloproteinase; TIMP, tissue inhibitor of matrix metalloproteinase. 
in proteolytic remodeling of ECM in various physiological pathways, including tissue development, tissue repair and angiogenesis (30). In the present study, the expression levels of MMP-2 and MMP-9, typical ECM-degrading enzymes and their inhibitors, TIMP-2 and TIMP-1, throughout the hair cycle were investigated.

Bacterial infections of the hair follicle is considered as primarily being caused by Staphylococcus aureus. ECM is secreted by dermal papilla cells and involves a cyclic process composed of degradation and renewal, which is regulated by numerous factors, including growth factors, cytokines, hormones, adhesion molecules and associated enzymes (13-16). It has been reported that Wnt, TGF- $\beta$ /bone morphogenic protein, hepatocyte growth factor, and epidermal growth factor signaling pathways serve as key regulators of hair follicle development (31). As a downstream cytokine regulated by the aforementioned signaling pathways, MMP-9 is an important collagenase involved in ECM remodeling (32). Previous studies suggested that MMP-9 serves an important role in the hair cycle (25). In the present study, the expression and activity of MMP-9 fluctuated, demonstrating peak activity during the catagen phase and minimum activity during the telogen phase in mice. This suggests that MMP-9 contributes towards the hair cycle, which was also demonstrated in a previous study using MMP-9-/ mice (26).

It has been hypothesized that other MMPs, such as MMP-2, may compensate for the effects of MMP-9 on hair canal formation in MMP- $9^{-/-}$mice, including the changing of the width of the hair canal and the dynamics of its formation (26). In the current study, it was demonstrated that the activity of MMP-2 fluctuated throughout the hair cycle, similarly to MMP-9. However, the activity of MMP-2 was much stronger compared with MMP-9, which is consistent with the findings of a previous in vitro study (33). Using immunohistochemical analysis, it was observed that in addition to the localization of MMP-9, MMP-2 was visualized at other localizations of the hair follicle at the same stage. These results support the hypothesis that MMP-2 contributes to the hair cycle in vivo and may compensate for the effects of MMP-9 on hair canal formation in MMP- $9^{-/}$mice.

Divano et al (34) reported that the expression levels of collagen fluctuate with regards to the hair cycle. The results demonstrate that collagen expression levels increased suddenly and significantly during the first 84 days of the telogen phase, whereas it decreased in the last week of the phase (34). The results regarding the activities of MMP-2 and MMP-9 in the present study may explain these data. Following ECM degradation and remodeling, MMP-2 and MMP-9 may affect the hair cycle by releasing growth factors from the ECM, and by stimulating cell migration (35) or activating growth factors, such as TGF- $\beta$ (36). This strongly suggests that MMP-2 may serve an important role in the hair growth cycle.

In the current study, TIMP-1 and TIMP-2 expression levels were demonstrated to fluctuate throughout the hair growth cycle. As expected, the expression levels of TIMP-1 and TIMP-2 were negatively correlated to those of MMP-9 and MMP-2 respectively, implying a negative correlation between MMPs and TIMPs. Similar to previous immunostaining and histological studies, strong correlations were observed between MMPs and TIMPs (37). However, the mRNA and protein expression levels of TIMP-1 and TIMP-2 were higher when compared with those of MMP-9 and MMP-2, respectively. In addition to inhibition of MMPs, TIMPs are demonstrated to be multifunctional; for instance, TIMP-2 is required for the activation of MMP-2, and TIMP-1 has been shown to act as a growth factor (38). This suggests that the balance between the expression levels of MMP-9 and TIMP-1, and of MMP-2 and TIMP-2 may functionally contribute towards the hair growth cycle.

In conclusion, the present study demonstrated that the expression levels and activities of MMP-2 and MMP-9 fluctuate throughout the hair growth cycle, and may be involved in its regulation. However, the mechanism underlying the regulation of the hair growth cycle by the enzymes requires further investigation.

\section{Acknowledgements}

The present study was supported by the Natural Science Foundation of China (grant nos. 31170949 and 81471900), the Key Clinical Specialty Discipline Construction Program, the Specialized Research Fund for the Doctoral Program of Higher Education (grant no. 20124433110012), the Natural Science Foundation of the Guangdong (grant no. S2012010009454) and the Dean Fund (grant no. 2013Z013).

\section{References}

1. Werb Z and Chin JR: Extracellular matrix remodeling during morphogenesis. Ann NY Acad Sci 857: 110-118, 1998.

2. Stenn KS and Paus R: Controls of hair follicle cycling. Physiol Rev 81: 449-494, 2001.

3. Morisaki N, Ohuchi A and Moriwaki S: The role of neprilysin in regulating the hair cycle. PLoS One 8: e55947, 2013.

4. Lu P, Takai K, Weaver VM and Werb Z: Extracellular matrix degradation and remodeling in development and disease. Cold Spring Harb Perspecti Biol 3: a005058, 2011.

5. Kähäi/i VM and Saariallio-Kere U: Matrix metalloproteinases in skin. Exp Dermatol 6: 199-213, 1997.

6. Fowlkes JL, Enghild JJ, Suzuki K and Nagase H: Matrix metalloproteinases degrade insulin-like growth factor-binding proein-3 in dermal fibroblast cultures. J Biol Chem 269: 25742-25746, 1994.

7. Björnberg F, Lantz M, Olsson I and Gullberg U: Mechanisms involved in the processing of the p55 and the p75 tumor necrosis factor (TNF) receptors to soluble receptor forms. Lymphokine Cytokine Res 13: 203-211, 1994.

8. Levi E, Fridman R, Miao HQ, Ma YS, Yayon A and Vlo-davsky I: Matrix metalloproteinase 2 releases active soluble ectodomain of fibroblast growth factor receptor 1. Proc Natl Acad Sci USA 93: 7069-7074, 1996.

9. Patterson BC and Sang QA: Angiostatin-converting en-zyme activities of human matrilysin (MMP-7) and gelatinase B/type IV collagenase (MMP-9). J Biol Chem 272: 28823-28825, 1997.

10. Brooks PC, Silletti S, von Schalscha TL, Friedlander M and Cheresh DA: Disruption of angiogenesis by PEX, a noncata-lytic metalloproteinase fragment with integrin binding activity. Cell 92: 391-400, 1998.

11. Woessner JF Jr: Matrix metalloproteinases and their inhibitors in connective tissue remodeling. FASEB J 5: 2145-2154, 1991.

12. Falkenburg JH, Harrington MA, de Paus RA, Walsh WK, Daub R, Landegent JE and Broxmeyer HE: Differential transcriptional and posttranscriptional regulation of gene expression of the colony-stimulating factors by interleukin- 1 and fetal bovine serum in murine fibroblasts. Blood 78: 658-665, 1991.

13. Brown PD, Levy AT, Margulies I, Liotta LA and Stetler-Stevenson WG: Independent expression and cellular processing of $\mathrm{Mr} 72,000$ type IV collagenase and interstitial collagenase in human tumorigenic cell lines. Cancer Res 50: 6184-6191, 1990 
14. Hujanen ES, Väisänen A, Zheng A, Tryggvason K and Turpeenniemi Hujanen T: Modulation of M(r) 72,000 and M(r) 92,000 type-IV collagenase (gelatinase A and B) gene expression by interferons a and gamma in human melanoma. Int J Cancer 58: 582-586, 1994.

15. Singh RK, Gutman M, Reich R and Bar-Eli M: Ultraviolet B irradiation promotes tumorigenic and metastatic properties in primary cutaneous melanoma via induction of interleukin 8 . Cancer Res 55: 3669-3674, 1995.

16. Wu B, Crampton SP and Hughes CC: Wnt signaling induces matrix metalloproteinase expression and regulates $\mathrm{T}$ cell transmigration. Immunity 26: 227-239, 2007.

17. Okada Y, Tsuchiya H, Shimizu H, Tomita K, Nakanishi I, Sato H, Seiki M, Yamashita K and Hayakawa T: Induction and stimulation of 92-kDa gelatinase/type IV collagenase production in osteosarcoma and fibrosarcoma cell lines by tumor necrosis factor alpha. Biochem Biophys Res Commun 171: 610-617, 1990.

18. Welch DR, Fabra A and Nakajima M: Transforming growth factorb stimulates mammary adenocarcinoma cell invasion and metastatic potential. Proc Natl Acad Sci USA 87: 7678-7682, 1990.

19. Samuel SK, Hurta RA, Kondaiah P, Khalil N, Turley EA, Wright JA and Greenberg AH: Autocrine induction of tumor protease production and invasion by a metallothionein-regulated TGF-beta 1 (Ser223, 225). EMBO J 11: 1599-1605, 1992.

20. Lyons RM, Gentry LE, Purchio A and Moses HL: Mechanism of activation of latent recombinant transforming growth factor beta 1 by plasmin. J Cell Biol 110: 1361-1367, 1990.

21. Kondapaka SB, Fridman R and Reddy KB: Epidermal growth factor and amphiregulin up-regulate matrix metalloprotein-ase- 9 (MMP-9) in human breast cancer cells. Int J Cancer 70: 722-726, 1997.

22. Nagase H: Activation mechanisms of matrix metalloproteinases. Biol Chem 378: 151-160, 1997.

23. Hou C, Miao Y, Wang J, Wang X, Chen CY and Hu ZQ Collagenase IV plays an important role in regulating hair cycle by inducing VEGF, IGF-1, and TGF- $\beta$ expression. Drug Des Devel Ther 9: 5373-5383, 2015.

24. Sharov AA, Schroeder M, Sharova TY, Mardaryev AN, Peters EM, Tobin DJ and Botchkarev VA: Matrix metalloproteinase-9 is involved in regulation of the hair canal formation. J Invest Dermatol 131: 257-260, 2011.

25. Larson B, Banks P, Sherman H and Rothenberg M: Automation of cell-based drug absorption assays in 96-well format using permeable support systems. J Lab Autom 17: 222-232, 2012.

26. Chen Y, Wei X, Guo C, Jin H, Han Z, Han Y, Qiao T, Wu K and Fan D: Runx3 suppresses gastric cancer metastasis through inactivation of MMP9 by upregulation of TIMP-1. Int J Cancer 129 : 1586-1598, 2011.
27. Nyhlin N, el-Salhy M, Sandstrom O and Suhr O: Evaluation of immunohistochemical staining of human duodenal endocrine cells after microwave antigen retrieval. Histochem J 29: 177-181, 1997.

28. Warford A, Akbar H and Riberio D: Antigen retrieval, blocking, detection and visualisation systems in immunohistochemistry: A review and practical evaluation of tyramide and rolling circle amplification systems. Methods 70: 28-33, 2014.

29. Tasseff R, Bheda-Malge A, DiColandrea T, Bascom CC, Isfort RJ and Gelinas R: Mouse hair cycle expression dynamics modeled as coupled mesenchymal and epithelial oscillators. PLoS Comput Biol 10: e1003914, 2014.

30. Patruno A, Pesce M, Marrone A, Speranza L, Grilli A, De Lutiis MA, Felaco M and Reale M: Activity of matrix metallo proteinases (MMPs) and the tissue inhibitor of MMP (TIMP)-1 in electromagnetic field-exposed THP-1 cells. J Cell Physiol 227: 2767-2774, 2012.

31. Schmidt-Ullrich R and Paus R: Molecular principles of hair follicle induction and morphogenesis. Bioessays 27: 247-261, 2005.

32. Gordon GM, Ledee DR, Feuer WJ and Fini ME: Cytokines and signaling pathways regulating matrix metalloproteinase-9 (MMP-9) expression in corneal epithelial cells. J Cell Physiol 221: 402-411, 2009.

33. Jarrousse F, Boisnic S, Branchet MC, Beranger JY, Godeau G, Breton L, Bernard BA and Mahé YF: Identication of clustered cells in human hair follicle responsible for MMP-9 gelatinolytic activity: Consequences for the regulation of hair growth. Int J Dermatol 40: 385-392, 2001

34. Divano C, Cardo P, Cipriani C and Pellerano S: Soluble and insoluble collagen and elastin in the rat hair cycle. Arch Dermatol Res 266: 135-141, 1979.

35. Yamazaki M, Tsuboi R, Lee YR, Ishidoh K, Mitsui S and Ogawa H: Hair cycle-dependent expression of hepatocyte growth factor (HGF) activator, other proteinases and proteinase inhibitors correlates with the expression of HGF in rat hair follicles. J Investig Dermatol Symp Proc 4: 312-315, 1999.

36. Wang M, Zhao D, Spinetti G, Zhang J, Jiang LQ, Pintus G, Monticone R and Lakatta EG: Matrix metalloproteinase 2 activation of transforming growth factor-betal (TGF-betal) and TGF-betal-type II receptor signaling within the aged arterial wall. Arterioscler Thromb Vasc Biol 26: 1503-1509, 2006.

37. Sugita H, Osaka S, Toriyama M, Osaka E, Yoshida Y, Ryu J, Sano M, Sugitani M and Nemoto N: Correlation between the histological grade of chondrosarcoma and the expression of MMPs, ADAMTSs and TIMPs. Anticancer research 24: 4079-4084, 2004.

38. Yang HK, Jeong KC, Kim YK and Jung ST: Role of matrix metalloproteinase (MMP) 2 and MMP-9 in soft tissue sarcoma. Clin Orthop Surg 6: 443-454, 2014. 